\title{
THE
}

\section{Further evidence that the sound-speed algorithm of Del Grosso is more accurate than that of Chen and Millero}

Christopher S. Meinen

University of Rhode Island

D. Randolph Watts

University of Rhode Island, randywatts@uri.edu

Follow this and additional works at: https://digitalcommons.uri.edu/gsofacpubs

Terms of Use

All rights reserved under copyright.

\section{Citation/Publisher Attribution}

Meinen, C. S., \& Watts, D. R. (1997). Further evidence that the sound-speed algorithm of Del Grosso is more accurate than that of Chen and Millero. Journal of the Acoustical Society of America, 102, 2058-2062. doi: 10.1121/1.419655.

Available at: https://doi.org/10.1121/1.419655

This Article is brought to you for free and open access by the Graduate School of Oceanography at DigitalCommons@URI. It has been accepted for inclusion in Graduate School of Oceanography Faculty Publications by an authorized administrator of DigitalCommons@URI. For more information, please contact digitalcommons-group@uri.edu. 


\section{Further evidence that the sound-speed algorithm of Del Grosso is more accurate than that of Chen and Millero}

Christopher S. Meinen, and D. Randolph Watts

Citation: The Journal of the Acoustical Society of America 102, 2058 (1997); doi: 10.1121/1.419655

View online: https://doi.org/10.1121/1.419655

View Table of Contents: http://asa.scitation.org/toc/jas/102/4

Published by the Acoustical Society of America

\section{Articles you may be interested in}

New equation for the speed of sound in natural waters (with comparisons to other equations)

The Journal of the Acoustical Society of America 56, 1084 (1974); 10.1121/1.1903388

A new equation for the accurate calculation of sound speed in all oceans

The Journal of the Acoustical Society of America 124, 2774 (2008); 10.1121/1.2988296

On equations for the speed of sound in seawater

The Journal of the Acoustical Society of America 93, 255 (1993); 10.1121/1.405660

Speed of sound in seawater as a function of salinity, temperature, and pressure

The Journal of the Acoustical Society of America 97, 1732 (1995); 10.1121/1.413048

Speed of sound in seawater at high pressures

The Journal of the Acoustical Society of America 62, 1129 (1977); 10.1121/1.381646

Comments on "On equations for the speed of sound in seawater" [J. Acoust. Soc. Am. 93, 255-275 (1993)]

The Journal of the Acoustical Society of America 95, 2757 (1994); 10.1121/1.409844 


\title{
Further evidence that the sound-speed algorithm of Del Grosso is more accurate than that of Chen and Millero
}

\author{
Christopher S. Meinen and D. Randolph Watts \\ Graduate School of Oceanography, University of Rhode Island, Narragansett, Rhode Island 02882
}

(Received 9 December 1996; revised 13 March 1997; accepted 8 July 1997)

\begin{abstract}
Estimates of the bottom depth of the ocean at 11 sites were determined by combining round-trip acoustic travel time measurements made by inverted echo sounders on the ocean bottom with sound-speed profiles determined from simultaneously measured temperature and salinity profiles. These depths were converted into pressures and were compared to independently measured bottom pressures to determine the accuracy of the algorithms used to calculate the sound-speed profile. The sound-speed algorithms tested were those derived by Del Grosso [J. Acoust. Soc. Am. 56, 10841091 (1974)] and by Chen and Millero [J. Acoust. Soc. Am. 62, 1129-1135 (1977)], as well as the corrected version of Chen and Millero's algorithm recently published by Millero and Li [J. Acoust. Soc. Am. 95, 2757-2759 (1994)]. The results of this study agree with the results from recent acoustic tomography experiments which indicate that the algorithm of Del Grosso for the speed of sound in seawater is more accurate than the currently accepted standard algorithm of Chen and Millero. Del Grosso's algorithm also produces more accurate results than those from the Millero and $\mathrm{Li}$ correction to the Chen and Millero algorithm. (C) 1997 Acoustical Society of America. [S0001-4966(97)05610-5]
\end{abstract}

PACS numbers: 43.30.Es [SAC-B]

\section{INTRODUCTION}

The algorithm of Chen and Millero ${ }^{1}$ for sound speed in seawater is the internationally accepted standard for use with hydrographic data, ${ }^{2}$ however, recent acoustic tomography work by Spiesberger and Metzger, ${ }^{3}$ Dushaw et al., ${ }^{4}$ and Spiesberger, ${ }^{5}$ has indicated that the sound-speed algorithm presented in Del Grosso ${ }^{6}$ is more accurate. The two algorithms calculate about the same sound-speed profile in the upper 1000 dbars, but Del Grosso's algorithm calculates speeds that are slower by about $0.8 \mathrm{~m} \mathrm{~s}^{-1}$ at depths of 5000 dbars. (The unit for pressure used here is the decibar, or dbar for short, which is equal to $10^{4}$ Pascals. Oceanographers commonly report pressure in dbars rather than the SI units of Pascals because $1 \mathrm{dbar} \approx 1 \mathrm{~m}$ of depth in the ocean.) Recently, a correction to the Chen and Millero algorithm for low temperatures and high pressures was published by Millero and $\mathrm{Li}^{7}{ }^{7}$ This correction reduces the difference between the two algorithms, but the corrected algorithm also consistently predicts higher sound speeds in the deep water than Del Grosso's algorithm. This study provides further evidence to support Del Grosso's algorithm by comparing pressures measured by pressure sensors to pressures estimated from acoustic travel time measurements made by inverted echo sounders.

\section{DATA}

Inverted echo sounders (IESs) are instruments moored about one meter off the ocean bottom that measure the time for $10-\mathrm{kHz}$ pulses to travel the round-trip distance to the ocean surface and back. ${ }^{8,9}$ PIES are IESs that are also equipped with pressure sensors from Paroscientific Inc., which are based on oscillating quartz crystals to which tension is applied via a Bourdon tube. ${ }^{10}$
If the sound-speed profile through the water column above the PIES is known concurrently with the travel time measurement, it is possible to combine this information to derive an estimate of the bottom depth. Full-water-column CTD (conductivity-temperature-depth) profiles obtained near each PIES site allowed for the calculation of soundspeed profiles as functions of temperature, salinity, and pressure using any of the three sound-speed algorithms.

This study was based upon 11 PIES records which have one or more full-water-column CTD profiles taken at the PIES site during the period of deployment. Four of the PIES were located in a line across the North Atlantic current at pressures of 3300-4900, ${ }^{11}$ six were in a line across the Kuroshio at pressures of $450-1100,{ }^{12}$ and the final PIES was located near Hawaii at a pressure of about 4800 dbars. ${ }^{13}$

\section{METHODS}

The travel time measurement, $\tau$, was used to estimate the bottom pressure in the following manner. The round-trip travel time is given by

$$
\tau=2 \int_{-H}^{0} \frac{1}{c} d z
$$

where $H$ is the depth of the acoustic transducer and $c$ is the sound speed. Defining

$$
\left\langle\frac{1}{c}\right\rangle=\frac{1}{H} \int_{-H}^{0} \frac{1}{c} d z
$$

Eq. (1) can be rearranged to give

$$
H=\frac{\tau}{2\langle 1 / c\rangle} .
$$


Sound-speed profiles were calculated from the CTD data using both the Del Grosso (hereafter DG74) and Chen and Millero (hereafter CM77) algorithms as well as the corrected Chen and Millero algorithm (hereafter ML94). These soundspeed profiles were then substituted into Eqs. (2) and (3) along with the concurrent travel times measured by the PIES to calculate the depths (in meters) of the PIES using each of the three sound-speed algorithms. These depths were then converted into pressures by making use of the equation described in Fofonoff and Millard. ${ }^{2}$ They give the following equation for converting from pressure to depth,

$$
z=\frac{C_{1} p+C_{2} p^{2}+C_{3} p^{3}+C_{4} p^{4}}{g(\phi)+\frac{1}{2} \gamma^{\prime} p}+\frac{\Delta D}{9.8},
$$

where $C_{1}=9.72659, \quad C_{2}=-2.2512 E-05, \quad C_{3}=2.279 E$ $-10, C_{4}=-1.82 E-15, \gamma^{\prime}=2.184 E-06 \mathrm{~m} \mathrm{~s}^{-2} \mathrm{dbar}^{-1}, p$ is the pressure, and $\Delta D$ is the dynamic height anomaly measured from pressure $p$ to the surface. This equation was inverted using an iterative method which resulted in pressures that are accurate to $0.1 \mathrm{dbars}$. These calculated pressures (in dbars) can be compared to the pressures measured by the pressure sensor located on the PIES. (There are a number of constant offsets that are inherent to the measurements of these instruments which must be accounted for as part of this procedure, as presented in the Appendix.)

\section{ERRORS IN THE MEASURED AND CALCULATED PRESSURES}

Before presenting the results of this comparison, a discussion of the errors involved in both the measurement of pressure and the calculation of pressure is in order. All errors quoted throughout this paper are at the one standard deviation level except where otherwise noted. Paroscientific states that the absolute accuracy of the pressure sensor measurement is $0.01 \%$ of full scale, about 0.5 dbars for instruments designed for up to $4500-\mathrm{m}$ depths. ${ }^{14}$ These Paroscientific pressure sensors have historically had problems with longterm drifts while deployed. However, recent work in the Gulf Stream has indicated that these drifts can be removed quite accurately. ${ }^{10}$ The linear drifts in the pressure sensors used here were all below $0.3 \mathrm{dbar}$ per year and most of them were less than 0.05 dbars per year. The travel time measurement of the IES is accurate to $1 \mathrm{~ms}^{9}{ }^{9}$ which is equivalent to an error in the calculated pressure of 0.75 dbars.

The largest source of error in the calculation results from the spatial offset between the PIES site and the location where the CTD is taken, which introduces random scatter due to the variation of the sound-speed profile caused by lateral gradients and internal waves and tides during the several hours involved in the CTD measurement. These errors are difficult to quantify; however, based on the maximum oceanic thermocline slope and the amplitude of tidal and higher frequency variability observed the combined error estimate is between 0.25 (at a CTD-PIES distance of $0 \mathrm{~km}$ ) and $2.5 \mathrm{dbars}$ (at a CTD-PIES distance of $3 \mathrm{~km}$ ). The specific CTD-PIES distances and errors are accounted for in the results section. Finally, errors in the sound-speed equations will also contribute to errors in the calculated pressure.
TABLE I. Calculated pressures compared to the pressure measured by the bottom pressure sensors. The locations of the instruments are noted. For sites where multiple CTDs were taken, the mean result from all of the casts is shown. Number of CTDs taken at each site is noted. For the shallow sites in the Kuroshio, the ML94 correction to the CM77 algorithm was not used, as the correction is for low temperature and high pressure only.

\begin{tabular}{rrrrrl}
\hline \hline $\begin{array}{c}\text { Measured } \\
\text { pressure }\end{array}$ & $\begin{array}{c}\text { DG74 } \\
\text { (dbars) }\end{array}$ & $\begin{array}{r}\text { CM77 } \\
\text { (dbars) }\end{array}$ & $\begin{array}{c}\text { ML94 } \\
\text { (dbars) }\end{array}$ & $\begin{array}{c}\text { Number of } \\
\text { CTD casts } \\
\text { at site }\end{array}$ & Location \\
\hline 3313.3 & 3314.3 & 3315.2 & 3314.6 & 3 & North Atlantic \\
3944.8 & 3945.3 & 3946.4 & 3945.6 & 2 & Current \\
4814.0 & 4816.1 & 4817.6 & 4816.5 & 1 & \\
4978.2 & 4977.9 & 4979.4 & 4978.3 & 2 & \\
4812.4 & 4814.4 & 4815.9 & 4814.8 & 9 & Hawaii \\
495.1 & 496.7 & 496.7 & N/A & 1 & Kuroshio \\
1098.1 & 1097.6 & 1097.7 & N/A & 1 & \\
1100.9 & 1100.9 & 1101.1 & N/A & 1 & \\
540.0 & 538.9 & 538.9 & N/A & 1 & \\
495.2 & 496.1 & 496.1 & N/A & 1 & \\
531.9 & 531.4 & 531.4 & N/A & 1 & \\
\hline \hline
\end{tabular}

DG74 and ML94 both quote an accuracy of $0.05 \mathrm{~m} \mathrm{~s}^{-1}$, which translates to a maximum potential error in the calculated pressure of about 0.2 dbars. CM77 quotes an accuracy of $0.2 \mathrm{~m} \mathrm{~s}^{-1}$, resulting in a maximum potential error of about 0.8 dbars in the calculated pressure.

\section{RESULTS}

Table I lists the measured pressures at the 11 PIES sites, together with the mean of the calculated pressures from all CTDs at each site, using CM77, ML94, and DG74. (ML94 was not used to calculate pressures at the shallow sites from the Kuroshio because the correction is for low temperatures and high pressures.) At the shallow (400-1000 m) sites from the Kuroshio, the agreement between the calculated pressures and the measured pressures is generally quite good, and there is little difference between the pressures calculated using DG74 and CM77. This is to be expected since DG74 and CM77 give very similar sound-speed profiles above 1000 dbars. Figure 1(A) shows that instruments located at shallow depths have calculated pressures about equal to the measured pressures, within the range of the scatter. Because of the good agreement between the calculated and measured pressures at these sites, the rest of this discussion will focus on the differences found at the deep sites.

\section{A. Relative differences between algorithms}

At depths greater than $3000 \mathrm{~m}$ the calculated pressures are consistently higher than the measured pressures. Figures 1B-D show that for these sites the pressures calculated using DG74 are about 1-1.5 dbars closer to the measured pressures than those calculated by CM77. The pressures calculated using ML94 are 0.3-0.4 dbars larger than those from DG74. These differences are significant because the only dissimilarities between the different methods of calculation are the sound-speed algorithms used. The above-quoted soundspeed algorithm accuracies explain a difference of $\sqrt{0.8^{2}+0.2^{2}}=0.82$ dbars between DG74 and CM77 and 

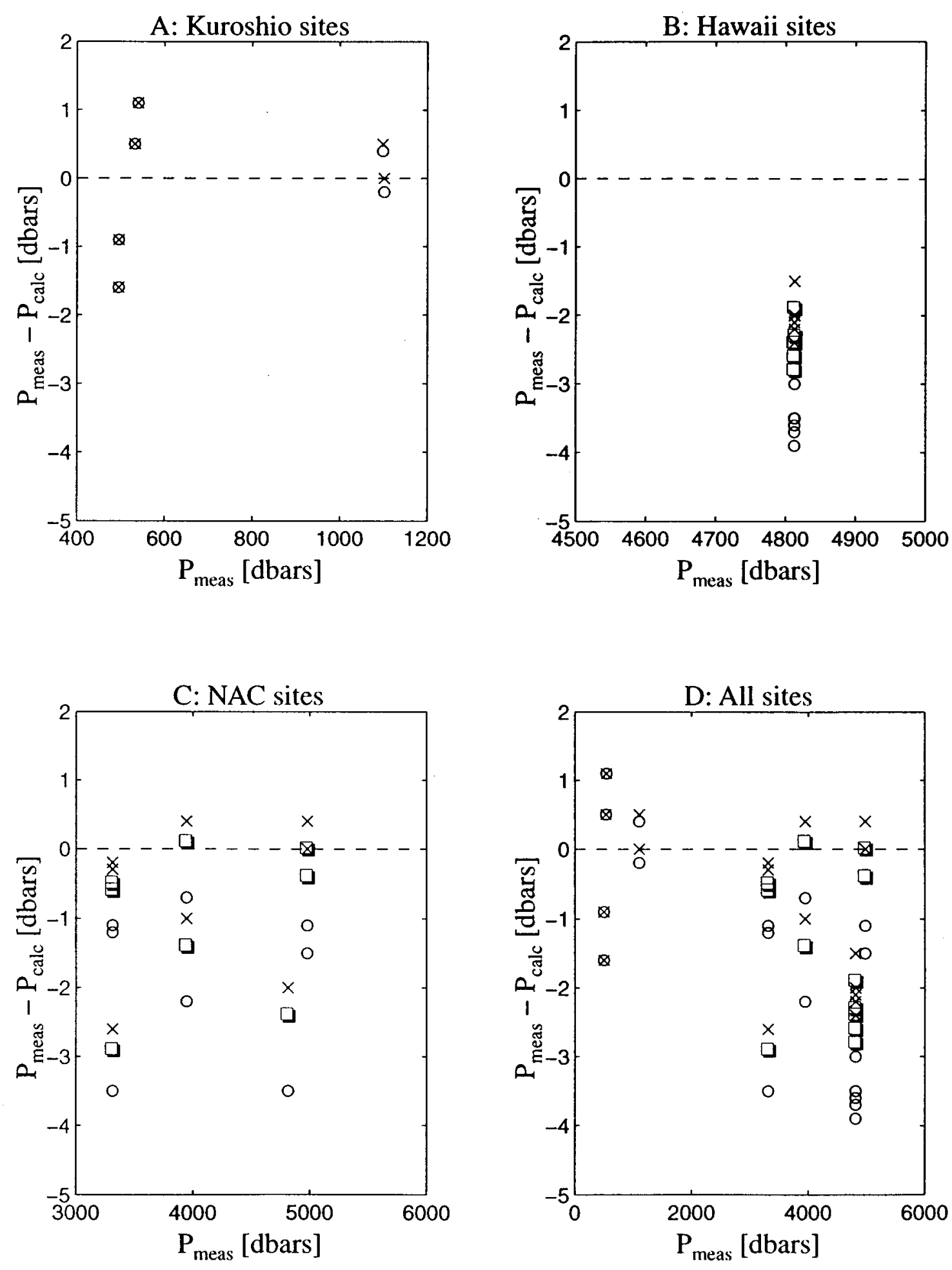

FIG. 1. Pressure difference ( $\left.P_{\text {measured }}-P_{\text {calculated }}\right)$ plotted vs $P_{\text {measured }}$, where pressures calculated using DG74 are denoted by crosses, pressures calculated using CM77 are denoted by circles, and pressures calculated using ML94 are denoted by open boxes. Panel A shows the sites from the Kuroshio, panel B shows the site near Hawaii, panel C shows the sites in the North Atlantic Current, and panel D shows all of the sites together. Results from all CTDs are shown. Dashed line denotes zero error.

$\sqrt{0.2^{2}+0.2^{2}}=0.28 \mathrm{dbars}$ between DG74 and ML94. Thus for an individual PIES and CTD pair, the differences between pressures calculated using DG74 and CM77 or DG74 and ML94 would not be significant at the two standard deviation level. It is important to realize, however, that these offsets are appearing in the mean of 17 different CTD and PIES combinations, and thus it is necessary to consider the standard deviation of the mean. Conservatively, it can be said that there are at least five degrees of freedom, one for each independent PIES site, so the standard deviation of the 


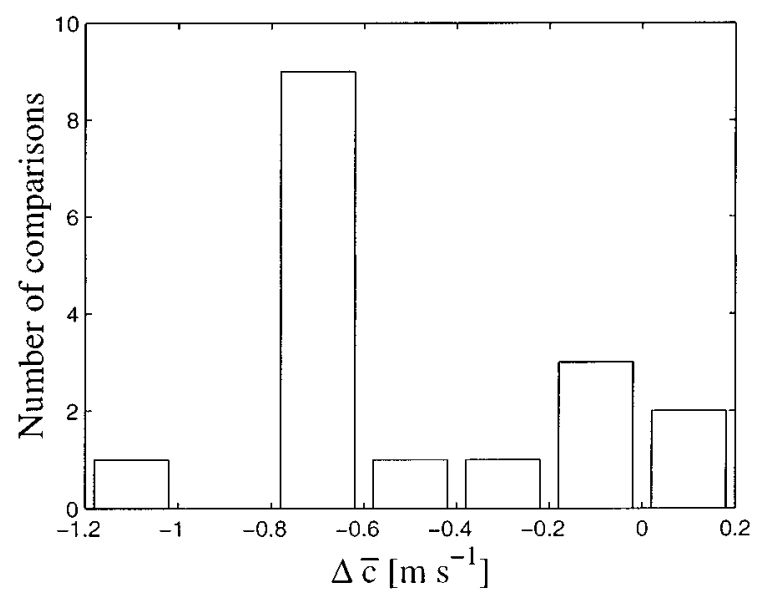

FIG. 2. Histogram of the change in the vertically averaged sound speed that would be necessary to make the calculated pressures (using DG74) at the deep (3000-5000 m) sites equal to the measured pressures.

mean offset between DG74 and CM77 is 0.37 , and it is 0.13 dbars between DG74 and ML94. Thus even at the two standard deviation level there are statistically significant differences between the pressures calculated using DG74 and those calculated using CM77 and ML94.

\section{B. Absolute differences between measured and calculated pressures}

The mean differences between the measured pressures at the deep sites and those calculated at the same sites using DG74, CM77, and ML94 are 1.4, 2.7, and 1.7 dbars, respectively. The total error (one standard deviation level) estimated for the calculations, due mainly to the spatial offset between the CTD sites and the PIES sites, which have a mean separation of $1.5 \mathrm{~km}$, is $1.5 \mathrm{dbars}$ for the pressure calculations using DG74 and ML94, it is 1.6 dbars for the pressure calculation using CM77. The corresponding standard deviation of the means, once again assuming five degrees of freedom, is about 0.7 dbars for all three algorithms. Thus the differences between the measured pressures and those calculated using DG74 are (barely) not statistically significant at two-standard deviations of the mean, whereas the differences from the pressures calculated using CM77 are nearly twice the size of the $95 \%$ errors, and those calculated using ML94 are more than 20\% larger than can be accounted for by two standard deviations of the mean. These results indicate that DG74 calculates more accurate sound speeds in the deep ocean than both CM77 and its recently updated version, ML94.

Note, however, that even the pressures calculated by DG74 at the deep North Atlantic Current and Hawaii sites are consistently greater than the measured pressures. The amount by which the vertically averaged sound speed [from Eq. (2)] would need to change to eliminate the difference between measured and calculated pressure can be estimated by rearranging Eq. (3) to give $\Delta c / c \approx \Delta H / H \approx \Delta p / p$. Figure 2 demonstrates that for nearly all of the sites at depths greater than 3000 dbars, the vertical mean sound-speed needs to be reduced to bring the calculated pressures in line with the measured pressures. This observation is consistent with the results of Spiesberger and Metzger, ${ }^{3}$ who found that DG74 calculated speeds that were $0.22 \mathrm{~m} \mathrm{~s}^{-1}$ too fast at a depth of $3 \mathrm{~km}$. Including the correction from Spiesberger and Metzger $^{3}$ in DG74 decreases the calculated pressures by about 0.2-0.4 dbars for the deeper PIES sites (the effect on the shallow Kuroshio sites is negligible). In a later paper Spiesberger ${ }^{5}$ questioned his proposed correction by explaining that the offsets he noted could have been due to his model parameters rather than a problem with the DG74 algorithm. Essentially he enlarged his error bars to indicate that he had insufficient information to determine definitively whether DG74 was predicting speeds that were too fast in the deep water. The results of this study indicate that a correction of the same sign and of somewhat larger magnitude than that recommended by Spiesberger and Metzger ${ }^{3}$ would give better agreement between the calculated and measured pressures. A decrease in the vertically averaged sound speed of about $0.5 \mathrm{~m} \mathrm{~s}^{-1}$ would reduce the mean of the observed offsets between the directly measured pressures and the calculated pressures to zero. It is important to note, however, that the pressures calculated using DG74 are not statistically different than the measured pressures based on our estimate of the errors involved in this calculation, so these results cannot definitively state that DG74 is calculating speeds that are too fast. However, since two completely different types of experiments, Spiesberger's modeling of acoustic tomography data and this study's comparison of measured pressures to acoustically determined pressures, have both found that DG74 consistently results in deep sound speeds that are too fast, it seems likely that sound speeds calculated at depths greater than 1000 dbars are still too high.

\section{CONCLUSIONS}

This study involved data from three separate experiments: one in the Kuroshio during 1991-92, the second off Hawaii in 1991-92, and the third in the North Atlantic Current from 1993-95. By directly measuring bottom pressure and comparing it with calculated bottom depth and pressure from travel times measured by inverted echo sounders and sound speed calculated from coinciding full-water-column CTDs, this study has provided additional evidence that Del Grosso's ${ }^{6}$ sound-speed algorithm is more accurate than that of Chen and Millero. ${ }^{1}$ Del Grosso's algorithm provides more accurate velocities at depths even when the recently published correction ${ }^{7}$ for low temperatures and high pressures for Chen and Millero's algorithm is used. The results also suggest that even Del Grosso's sound-speed algorithm may be calculating speeds that are slightly too fast in water deeper than 1000 dbars. Further measurements would be required to confirm this hypothesis. Nevertheless, Del Grosso's algorithm is accurate enough to calculate bottom depths and pressures to within about $1 \mathrm{~m}$ and $1 \mathrm{dbar}$ in 5000 dbars. 


\section{ACKNOWLEDGMENTS}

The authors would like to express their sincere appreciation to Karen Tracey for her assistance in processing these data. Dr. Allyn Clarke and his colleagues at the Bedford Institute of Oceanography in Halifax, Nova Scotia provided some of the CTD profiles taken at the sites in the North Atlantic Current. Dr. Mark Wimbush at the University of Rhode Island kindly provided all of the Kuroshio data. Dr. Steve Chiswell of the New Zealand Oceanographic Institute provided the data from Hawaii. Mr. Richard Wearn at Paroscientific Inc. provided a considerable amount of information concerning the accuracy of the pressure sensors. Dr. John Spiesberger at Pennsylvania State University and Dr. Nicholas Fofonoff at the Woods Hole Oceanographic Institute also provided helpful suggestions. The authors would also like to thank the reviewers, who made a number of very helpful suggestions. This project was funded under NOAA Grant No. NA56GP0134.

\section{APPENDIX: INHERENT OFFSETS IN THE PIES}

Both the travel time and pressure measurements made by the PIES are subject to some constant offsets which are compensated for here. There is a fixed 3-ms internal response delay in the IES, which must be subtracted from the measured travel time to avoid overestimating the depth of the IES. The pressure sensors measure absolute pressure, rather than gauge pressure, so the atmospheric pressure must be removed from the measured pressure, because the PIES measures the acoustic travel time relative to the sea surface. Since variations of atmospheric pressure are on the order of a tenth of a decibar, it is sufficient to subtract the annual mean regional value of atmospheric pressure $(10.2,10.2$, and 10.1 dbars for, respectively, the North Atlantic Current, Hawaii, and Kuroshio regions). Last, the pressure sensor on the PIES is located $0.58 \mathrm{~m}$ below the acoustic transducer, so for comparison to the pressure estimated from the travel time, the corresponding small hydrostatic offset (0.60 dbars) was subtracted from the measured pressure.

${ }^{1}$ C.-T. Chen and F. J. Millero, "Speed of sound in seawater at high pressures," J. Acoust. Soc. Am. 62, 1129-1135 (1977).

${ }^{2}$ N. P. Fofonoff and R. C. Millard, "Algorithms for computation of fundamental properties of seawater," UNESCO Technical Papers in Marine Science, No. 44 (1983).

${ }^{3}$ J. L. Spiesberger and K. Metzger, "A new algorithm for sound speed in seawater," J. Acoust. Soc. Am. 89, 2677-2688 (1991).

${ }^{4}$ B. D. Dushaw, P. F. Worcester, B. D. Cornuelle, and B. M. Howe, "On equations for the speed of sound in seawater," J. Acoust. Soc. Am. 93, 255-275 (1993)

${ }^{5}$ J. L. Spiesberger, "Is Del Grosso's sound-speed algorithm correct?," J. Acoust. Soc. Am. 93, 2235-2237 (1993).

${ }^{6}$ V. A. Del Grosso, "New equation for the speed of sound in natural waters (with comparisons to other equations)," J. Acoust. Soc. Am. 56, 10841091 (1974).

${ }^{7}$ F. J. Millero and X. Li, "Comments on "'On equations for the speed of sound in seawater","' J. Acoust. Soc. Am. 95, 2757-2759 (1994).

${ }^{8}$ D. R. Watts and H. T. Rossby, "Measuring dynamic heights with Inverted Echo Sounders: Results from MODE,' J. Phys. Oceanogr. 7(3), 345-358 (1977)

${ }^{9}$ G. F. Chaplin and D. R. Watts, "Inverted Echo Sounder development," Proc. Oceans, 249-253 (1984).

${ }^{10}$ D. R. Watts and H. Kontoyiannis, "Deep-ocean bottom pressure measurement: Drift removal and performance,'” J. Atmos. Oceanic Technol. 7(2), 296-306 (1990).

${ }^{11}$ K. L. Tracey, C. S. Meinen, and D. R. Watts, "North Atlantic Current inverted echo sounder data report for August 1993-July 1995,', Technical Report 7, Graduate School of Oceanography, University of Rhode Island, Narragansett, Rhode Island, 1996.

${ }^{12}$ C. James, M. Wimbush, and H. Ichikawa, "East China Sea, Kuroshio 1991-2 Data Report," Technical Report 3, Graduate School of Oceanography, University of Rhode Island, Narragansett, Rhode Island, 1994.

${ }^{13}$ S. M. Chiswell, "Using an array of Inverted Echo Sounders to measure dynamic height and geostrophic current in the North Pacific subtropical gyre,' J. Atmos. Oceanic Technol. 11(5), 1420-1424 (1994).

${ }^{14}$ R. B. Wearn, 1996 (personal communication). 